\title{
Pollen diversity in selected species of the tribe Chironieae [Gentianaceae Juss.] that occur in the Atlantic Forest, Brazil
}

\author{
Hian Carlos Ferreira de Sousa', Vania Gonçalves-Esteves and Cláudia Barbieri Ferreira Mendonça ${ }^{1 *}$
}

Received: November 29, 2016

Accepted: February 22, 2017

\begin{abstract}
Based on molecular data, the tribe Chironieaea (Gentianaceae) is divided into three subtribes. This study aims to describe the pollen morphology of representatives of two of the three subtribes that occur in the Atlantic Forest in order to contribute to a better understanding of the palynology of these taxa and to clarify the taxonomy of the family: subtribe Chironiinae (Centaurium erythraea and Zygostigma australe) and subtribe Coutoubeinae (Coutoubea ramosa, C. spicata, Deianira chiquitiana, D. damazioi, D. erubescens, D. nervosa and D. pallescens). Botanical material was obtained from exsicates and treated by acetolysis for light microscopy. Pollen grains were measured and photomicrographed, and the results statistically analyzed. For SEM study, non-acetolyzed pollen grains were sprayed onto metal stubs. The results show that the pollen grains in Chironiinae are medium-sized, prolate-spheroidal or subprolate, 3-colporate, monads, with striate-reticulate ornamentation. In Coutoubeinae the pollen grains are large or medium-sized tetrads with aperture varying between 3-porate or 3-hemicolpates and the sexine microreticulate (D. erubescens) or varied reticulate (the other species). Pollen morphology proved to be an important tool for the systematics of the family since it corroborated the existing placement of species into subtribes based on molecular data.
\end{abstract}

Keywords: Chironiinae, Coutoubeinae, morphology, palynology, pollen grains

\section{Introduction}

Gentianaceae has a Cosmopolitan distribution and comprises about 87 genera and 1700 species (Struwe et al. 2002). The majority of the genera are found in South and Central America, accounting for $54 \%$ of the total number of genera in the family (Albert \& Struwe 2002). Thirty one genera and approximately 120 species of the family occur in Brazil (BFG 2015).

Gilg 1895 delimited Gentianaceae in a classification based solely on palynological characters, and the family was divided into five tribes. Struwe et al. (2002) proposed a new classification for the family based on molecular data and recognized six tribes.
Through molecular analysis, the tribe Chironieae, one of the six tribes of Gentianaceae, was divided into three subtribes: Canscorinea, Chironiinae and Coutoubeinae (Struwe et al. 2002). Canscorinea occurs in the Paleotropical Region with no representatives in Brazil, while the subtribe Chironiinae is found in temperate regions and is represented in Brazil by Zygostigma and Centaurium. The subtribe Coutoubeinae has an exclusively Neotropical distribution and contains the genus Coutoubea, Deianira, Schultesia, Symphyllophyton and Xestaea (Struwe et al. 2002). Chironieae has about 160 species distributed in 23 genera (Albert \& Struwe 2002). In the Atlantic Forest this tribe is represented by five genera and 15 taxa (BFG 2015).

\footnotetext{
${ }^{1}$ Museu Nacional, Universidade Federal do Rio de Janeiro, 20940040, Rio de Janeiro, RJ, Brazil

* Corresponding author: cb.mendonca@gmail.com
} 
Among Brazilian biomes, the Atlantic Forest has the greatest number of endangered species of plants, followed by the Cerrado, the two Brazilian hotspots of biodiversity (Myers et al. 2000). The main remnants of Atlantic Forest are concentrated in the South and Southeast regions of the country. In addition to this, the Southeast has the greatest number of endangered species (Martinelli \& Moraes 2013). Based on this statistic, the present study examined selected species of the tribe Chironieae found in this region of Brazil.

Few playnological studies have involved the family Gentianaceae. Among these, Nilsson (2002) created pollen types based on pollen morphology of species subordinate to three genus of the tribe Chironieae (Coutoubea, Deianira and Schultesia). Guimarães et al. (2003) analyzed the pollen morphology of Schultesia concluding that the genus was homogeneous, yet pollen attributes contributed to the formation of new subgenus. The genus Curtia and Hockinia were analyzed by Crespo \& Marcondes-Ferreira (2006), thus increasing knowledge of the palynology of the tribe Saccifolieae. Ferreira et al. (2012) studied the palynology of four genera occurring in a forest Reserve in the Amazon and found great variation in the morphology of species. The subtribe Swertiinae had its pollen grains studied and the results had phylogenetic implications (Chassot \& Hagen 2008).

Regarding the tribe Chironieae, there are few studies focusing on the palynology of the representatives of the Atlantic Forest biome. Among them are Makino (1991), who analyzed three species of the Reserva do Parque Estadual das Fontes do Ipiranga, and Guimarães et al. (2003), cited above. Because of the considerable variation in pollen characters, it is necessary to make available information on the pollen morphology of this tribe, with the purpose of providing support to help in the taxonomy of the family, by seeking characters that establish intergeneric and interspecific limits as well as data for future phylogenetic analyses.

\section{Materials and methods}

Samples were obtained from anthers of flower buds from specimens deposited in the herbaria $\mathrm{R}, \mathrm{RB}$ and $\mathrm{RBR}$ (Thiers et al. continuously update). The material used in the present study was listed according to the subtribe and in alphabetical order of species, followed by the main collection information ( $\mathrm{S} 1$ in supplementary material).

Voucher slides are stored in the pollen collection of the Laboratório de Palinologia, Departamento de Botânica, Museu Nacional, Universidade Federal do Rio de Janeiro (UFRJ).

Pollen grains were prepared for light microscopy (LM) according Melhem et al. (2003) modified version of the acetolysis treatment of Erdtman (1952), mounted in glycerine jelly, and observed at 1000x magnification under oil immersion. All measurements were obtained by LM within seven days of preparation (Salgado-Labouriau 1973). Images were captured on a Zeiss Axiostar Plus camera.

Non-acetolized pollen grains were analized by scanning electron microscopy (SEM). The material was placed on aluminium stubs covered with carbon tape and sputtercoated with gold-palladium for $3 \mathrm{~min}$. Samples were then examined using a Zeiss DSM 960 SEM in the Departamento de Invertebrados, Museu Nacional (Universidade Federal do Rio de Janeiro). The electron micrographs and photomicrographs were treated in Corel Draw X5, converted to grayscale, changing the contrast and brightness.

For species in monads, 25 pollen grains per sample were observed in equatorial view, the polar diameter (PD) and equatorial diameter (ED) per sample. Arithmetic mean (x), mean deviations (Sx) and $95 \%$ confidence intervals (CI) were calculated. For measurements of equatorial diameter from the polar view (EDPV), apocolpium (AP), aperture, and exine thickness, the arithmetic means of 10 measurements were used.

For species in tetrads were measured 25 pollen grains in basal or apical position, the diameter 1 (D1) and diameter 2 (D2). Means (x), means deviations (Sx) and $95 \%$ confidence intervals (CI) were calculated. For lateral position (D1L) the arithmetic means of 10 measurements were used.

The terminology used for pollen description follows Punt et al. (2007), which takes into consideration elements of size, form, number of apertures, and sexine ornamentation. Descriptions of polar area and aperture size were in accordance with the classification system established by Faegri \& Iversen (1966) for the polar area index. For pollen grains in tetrads the positions follow Guimarães et al. (2003).

\section{Results}

\section{General morphology}

The selected species belonging to the two subtribes analyzed presented the following results:

\section{Pollen unit and size}

In the subtribe Chironiinae, the pollen grains are monads of medium sized (Fig.1A-I), in Centaurium erythraea and Zygostigma australe (Tab. 1); isopolar and prolate spheroidal with a subtriangular amb (Fig. 1A) and a small polar area in Centaurium erythraea or subprolate with a subcircular amb (Fig. 1F) in Zygostigma australe (Tabs. 1-2).

In the subtribe Coutoubeinae the pollen grains are united in calymmate tetrahedral tetrads (Figs. 1J-L, 2A-L, 3A-L), large size in Coutoubea and Deianira nervosa, or mediumsize, in the other species of Deianira. The pollen grains that make up the tetrads are medium sized (Tab. 3). 

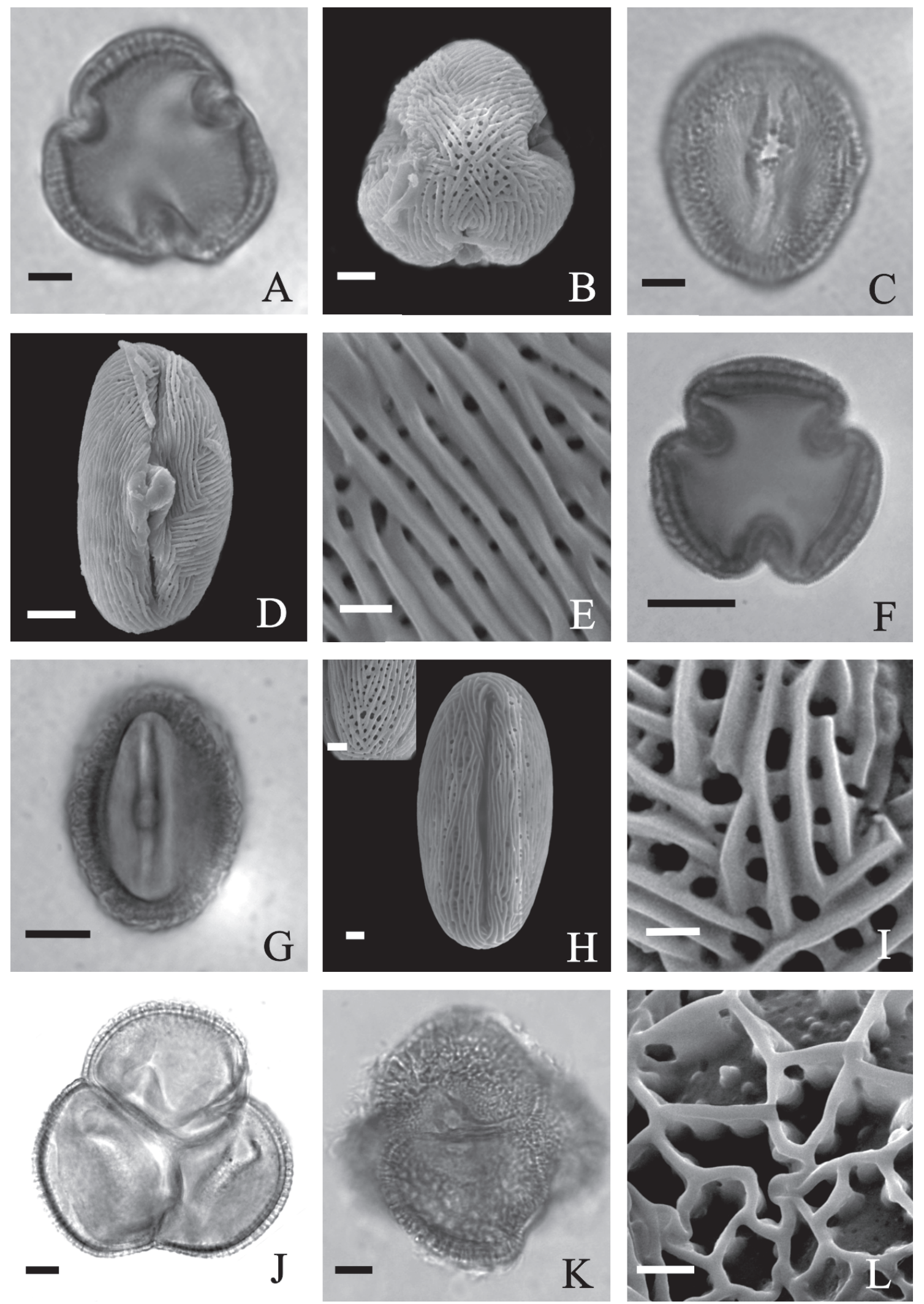

Figure 1. Photomicrographs and electron micrographs of pollen grains of species of Chironieae (Gentianaceae). A-E. Centaurium erythraea - polar view: A. optical section (LM), B. general view (SEM), equatorial view: C. aperture detail (LM), D. general view (SEM), E. surface detail (SEM). F-I. Zygostigma australe - polar view: F. optical section (LM), equatorial view: G. aperture detail (LM), H. general aspect (SEM), I. surface detail (SEM). J-L. Coutoubea ramosa - basal view: J. optical section (LM), lateral view (LM): K. aperture detail (LM), L. surface detail (SEM). Scales bar: A, F, G, J, K $=10 \mu \mathrm{m} ; \mathrm{B}, \mathrm{C}, \mathrm{D}=5 \mu \mathrm{m} ; \mathrm{H}, \mathrm{L}=2 \mu \mathrm{m} ; \mathrm{E}, \mathrm{I}=1 \mu \mathrm{m}$ 
Table 1. Measurements $(\mu \mathrm{m})$ of pollen grains in monads in equatorial view: polar diameter (PD); equatorial diameter (ED), species of Gentianaceae $(n=25)$.

\begin{tabular}{|l|c|c|c|c|c|c|c|c|}
\hline Species & \multicolumn{3}{|c|}{ Polar Diameter } & \multicolumn{3}{c|}{ Equatorial Diameter } & PD/ED & Shape \\
\hline & Range & $\overline{\mathrm{x}} \pm \mathrm{s}_{\overline{\mathrm{x}}}$ & C.I. 95\% & Range & $\overline{\mathrm{x}} \pm \mathrm{s}_{\mathrm{x}}$ & C.I. 95\% & & \\
\hline Centaurium erythraea & $25.0-32.5$ & $28.2 \pm 0.3$ & $27.7-28.9$ & $22.5-27.5$ & $26.2 \pm 0.3$ & $25.6-26.8$ & 1.07 & prolate spheroidal \\
\hline Zygostigma australe & $30.0-37.5$ & $33.1 \pm 0.3$ & $32.5-33.7$ & $22.5-30.0$ & $26.0 \pm 0.4$ & $25.2-26.8$ & 1.27 & subprolate \\
\hline
\end{tabular}

$\overline{\mathrm{x}} \pm \mathrm{s}_{\mathrm{x}}$ - arithmetic mean \pm standard deviation; $95 \%$ C.I. $-95 \%$ confidence interval; PD/ED - polar:equatorial

Table 2. Measurements ( $\mu \mathrm{m}$ ) of pollen grains in polar view: equatorial diameter in polar view (EDPV). side apocolpium (AL). polar area index (PAI) of Chironieae (Gentianaceae) $(n=10)$.

\begin{tabular}{|c|c|c|c|c|c|c|}
\hline Species & \multicolumn{2}{|c|}{ EDPV } & \multicolumn{2}{|c|}{ AL } & PAI & Polar area \\
\hline & Range & $\overline{\mathrm{x}}$ & Range & $\overline{\mathrm{x}}$ & & \\
\hline Centaurium erythraea & $27.5-30.0$ & 27.7 & $12.5-15.0$ & 12.6 & 0.45 & small \\
\hline Zygostigma australe & $25.0-27.5$ & 26.5 & $10.0-11.2$ & 10.2 & 0.39 & small \\
\hline
\end{tabular}

Table 3. Measurements $(\mu \mathrm{m})$ of diameter 1 and $2(n=25)$ and diameter 1 in lateral view (D1L) $(n=10)$ of tetrads and polar diameter (PD), equatorial diameter (ED) $(n=10)$ of pollen grains of species of Chironieae (Gentianaceae).

\begin{tabular}{|c|c|c|c|c|c|c|c|c|c|c|c|}
\hline \multirow{3}{*}{ Species } & \multicolumn{7}{|c|}{ Tetrads } & \multicolumn{4}{|c|}{ Pollen Grain } \\
\hline & \multicolumn{3}{|c|}{ D1 } & \multicolumn{3}{|c|}{ D2 } & \multirow{2}{*}{$\begin{array}{c}\text { D1L } \\
\overline{\mathrm{x}}\end{array}$} & \multicolumn{2}{|c|}{ PD } & \multicolumn{2}{|c|}{ ED } \\
\hline & Range & $\overline{\mathrm{x}} \pm \mathrm{s}_{\overline{\mathrm{x}}}$ & C.I. $95 \%$ & Range & $\overline{\mathrm{x}} \pm \mathrm{s}_{\overline{\mathrm{x}}}$ & C.I. $95 \%$ & & Range & $\overline{\mathrm{x}}$ & Range & $\overline{\mathrm{x}}$ \\
\hline Coutoubea ramosa & $67.5-82.5$ & $73.9 \pm 0.7$ & $72.4-75.3$ & $60.0-72.5$ & $67.0 \pm 0.7$ & $65.5-68.4$ & 70.2 & $32.5-42.5$ & 37.0 & $37.5-47.5$ & 43.2 \\
\hline Coutoubea spicata & $62.5-75.0$ & $66.8 \pm 0.5$ & $65.4-68.2$ & $52.5-65.0$ & $59.0 \pm 0.5$ & $57.9-60.1$ & 72.5 & $35.0-37.5$ & 36.5 & $37.5-47.5$ & 42.0 \\
\hline Deianira chiquitiana & $42.5-47.5$ & $45.1 \pm 0.3$ & $44.4-45.8$ & $37.5-42.5$ & $41.1 \pm 0.3$ & $40.4-41.8$ & 44.5 & $20.0-25.0$ & 22.5 & $25.0-30.0$ & 27.7 \\
\hline Deianira damazioi & $50.0-58.7$ & $53.1 \pm 0.4$ & $52.2-54.0$ & $42.5-52.5$ & $47.4 \pm 0.4$ & $46.6-48.3$ & 53.2 & $25.0-32.5$ & 29.0 & $32.5-37.5$ & 34.7 \\
\hline Deianira erubescens & $37.5-47.5$ & $42.6 \pm 0.5$ & $41.5-43.7$ & $35.0-45.0$ & $40.2 \pm 0.5$ & $39.1-41.3$ & 45.0 & $22.5-27.5$ & 25.5 & $25.0-32.5$ & 29.5 \\
\hline Deianira nervosa & $52.5-65.0$ & $57.7 \pm 0.6$ & $56.4-59.0$ & $47.5-60.0$ & $52.0 \pm 0.6$ & $50.7-53.3$ & 59.0 & $27.5-37.5$ & 30.7 & $32.5-42.5$ & 36.5 \\
\hline Deianira pallescens & $40.0-47.5$ & $44.5 \pm 0.4$ & $43.7-45.3$ & $35.0-45.0$ & $40.9 \pm 0.5$ & $39.9-41.8$ & 43.5 & $17.5-25.0$ & 21.7 & $25.0-32.5$ & 27.7 \\
\hline
\end{tabular}

Apertures

In the subtribe Chironiinae, the pollen grains are tricolporate, with long ectoapertures and circular endoapertures with ornamented margins (ca. de $2.3 \mu \mathrm{m}$ ) in Centaurium erythraea (Fig. 1C-D) or with endoapertures without ornamented margins in Zygostigma australe (Fig. 1G-H, Tab. 4).

In the subtribe Coutoubeinae, the aperture varies from 3-porate in species of Coutoubea (Fig. 1K, 2C) to 3-hemicolpate in species of Deianira (Fig. 2G-H, L, 3C-D, F-G, K-L).
Exine

Chironiinae possesses a striate-reticulate sexine with perforations in the mesocolpium and striate microreticulate in the apocolpium in Centaurium erythraea (Fig. 1B, E) or a striate reticulate sexine with larger lumina near the apocolpium in Zygostigma australe (Fig. 1H-I). In relation to the subtribe Coutoubeinae, the sexina varies: a) reticulate heterobrochate with lumina decreasing towards the apertural region in the genus Coutoubea, with sinuous and tall muri, with ornamented lumina in C. ramosa (Fig. 1L) or straight, low muri without ornamented lumina in C. spicata (Fig. 2D);

Table 4. Measurements $(\mu \mathrm{m})$ of the aperture of pollen grains of species of Chironieae (Gentianaceae) $(n=10)$.

\begin{tabular}{|l|c|c|c|c|c|c|}
\hline \multirow{2}{*}{ Species } & \multicolumn{3}{|c|}{ Pore } & \multicolumn{2}{c|}{ Colpus } & \multicolumn{2}{c|}{ Endoaperture } \\
\cline { 2 - 7 } & D1 & D2 & length & width & length & width \\
\hline Centaurium erythraea & - & - & 17.8 & 4.4 & 2.5 & 3.7 \\
\hline Zygostigma australe & - & - & 21.1 & 3.3 & - \\
\hline Coutoubea ramosa & 5.6 & 5.5 & - & - & - & - \\
\hline Coutoubea spicata & 5.5 & 5.3 & - & - & - \\
\hline Deianira chiquitiana & - & - & 5.8 & 2.0 & - & - \\
\hline Deianira damazioi & 5.1 & 4.8 & - & - & - & - \\
\hline Deianira erubescens & 3.0 & 2.8 & - & - & - & - \\
\hline Deianira nervosa & - & - & 5.0 & 2.8 & - \\
\hline Deianira pallescens & - & - & 5.9 & 2.9 & - \\
\hline
\end{tabular}



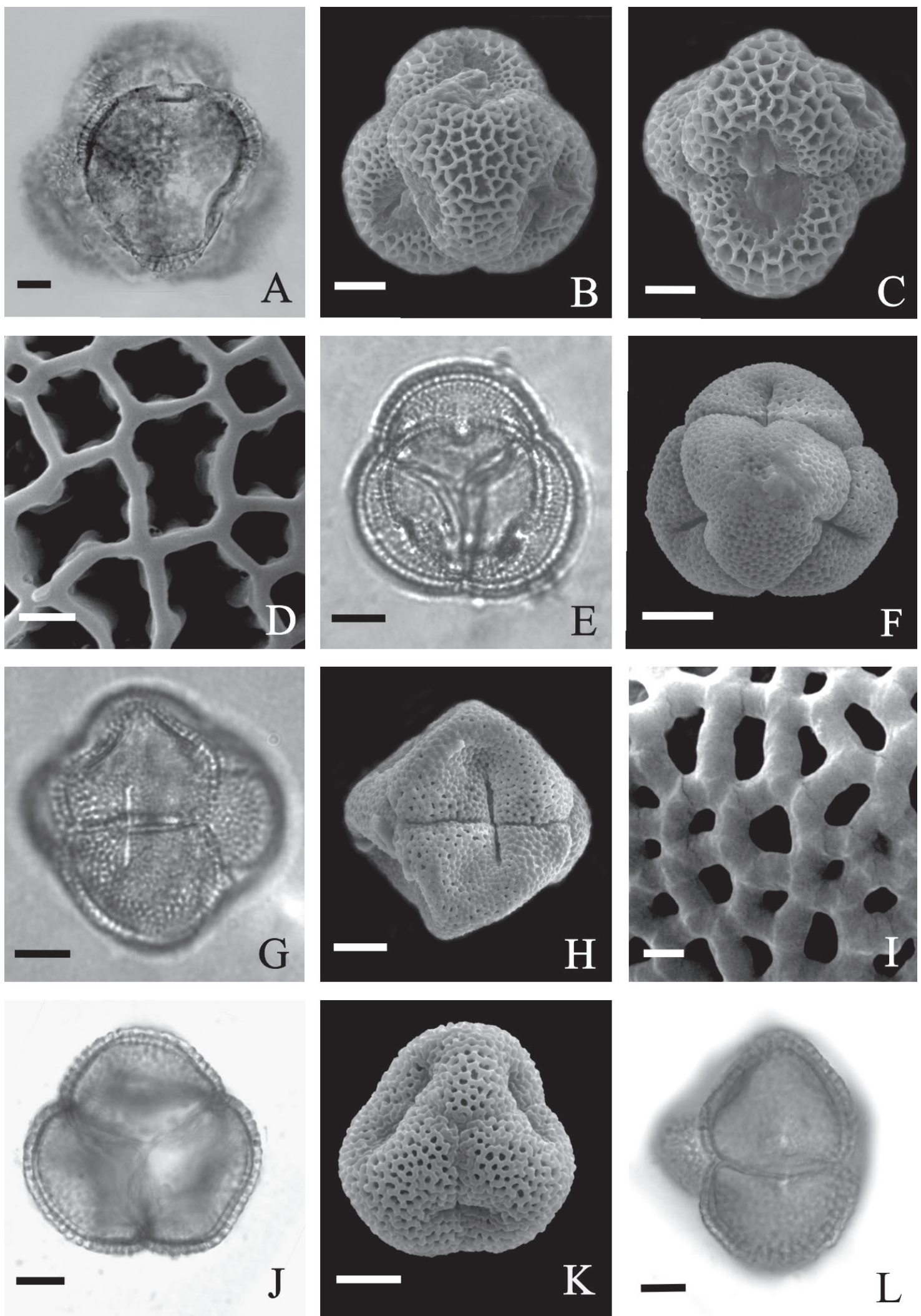

Figure 2. Photomicrographs and electron micrographs of pollen grains of species of Chironieae (Gentianaceae). A-D. Coutoubea spicata - apical view: A. optical section (LM), B general view (SEM), lateral view: C. general aspect (SEM), D. surface detail (SEM). E-I. Deianira chiquitiana - apical view: E. optical section (LM), F. general view (SEM), lateral view: G. aperture detail (LM), H. general aspect (SEM), I. surface detail (SEM). J-L. D. damazioi - basal view: J. optical section (LM), K. general view (SEM), lateral view: L. aperture detail (LM). Scales bar: A, B, C, F, G, H, I, J, K, L = $10 \mu \mathrm{m} ; \mathrm{D}=2 \mu \mathrm{m} ; \mathrm{E}=1 \mu \mathrm{m}$. 
b) reticulate with perforations, short, thic muri and a rounded surface in Deianira chiquitiana (Fig. 2G-I); c) reticulate with higher muri at the intersection of the lumina due to higher columellae and perforations near the apertural region in $D$. damazioi (Fig. $2 \mathrm{~K}$ ); d) microreticulate in $D$. erubescens (Fig. 3 C); e) reticulate with higher columellae at the points of intersection and granules in lumina in $D$. nervosa (Fig. 3G-H); f) reticulate with few perforations and large lumina in the mesocolpium, without high columellae and without ornamented lumina in D. pallescens (Fig. 3J, L). Most species possess a thicker sexine than nexine, with the exception of Deianira chiquitiana, which has the sexine as thick as the nexine (Tab. 5).

Table 5. Measurements $(\mu \mathrm{m})$ of the exine layers of pollen grains of species of Chironieae (Gentianaceae) $(n=10)$.

\begin{tabular}{|l|c|c|c|}
\hline Species & Exine & Sexine & Nexine \\
\hline Centaurium erythraea & 2.7 & 1.7 & 1.0 \\
\hline Zygostigma australe & 4.6 & 2.8 & 1.8 \\
\hline Coutoubea ramosa & 6.8 & 4.7 & 2.1 \\
\hline Coutoubea spicata & 5.7 & 3.5 & 2.2 \\
\hline Deianira chiquitiana & 2.0 & 1.0 & 1.0 \\
\hline Deianira damazioi & 3.5 & 2.1 & 1.4 \\
\hline Deianira erubescens & 2.5 & 1.6 & 0.9 \\
\hline Deianira nervosa & 4.4 & 2.9 & 1.5 \\
\hline Deianira pallescens & 2.8 & 1.8 & 1.0 \\
\hline
\end{tabular}

\section{Key to the pollen of the species of Chironieae (Gentianaceae)}

1. Pollen grains monads

2. Shape prolate spheroidal, endoaperture with ornamented margin Centaurium erythraea

2'. Shape subprolate, endoaperture without ornamented margin ..... Zygostigma australe

1'. Pollen grains tetrads

3. Pollen grains hemicolpate

4. Tetrads large, columellae higher at points of intersection of the lumina, lumina ornamented

4'. Tetrads medium size, without columellae higher at points of intersection of the lumina; lumina not ornamented

5. Sexine microreticulate

Deianira erubescens

5'. Sexine reticulate

6. Reticulations with larger lumina in the mesocolpium

Deianira pallescens

6 '. Reticulations with lumina not differeing in size throughout the entire surface

7. Reticulations with muri without convex surface, high at the intersection of the lumina; Confidence Interval $95 \%$ of Diameter $1>50.0 \mu \mathrm{m}$.

Deanira damazoi

7'. Reticulations with muri with convex surface; Confidence Interval $95 \%$ of Diameter $1<50,0 \mu \mathrm{m}$

Deianira chiquitiana

3'. Pollen grains porate

8. Reticulations with sinuous, high muri, with ornamented lumina; Size $>70 \mu \mathrm{m}$ Coutoubea ramosa

8'. Reticulations with low, straight muri, without ornamented lumina; Size $<70 \mu \mathrm{m}$ Coutoubea spicata

\section{Discussion}

All of the species analyzed herein could be separated based on the following characters: pollen unit (monads and tetrads), size of the monads (medium size) and tetrads (medium or large), shape (prolate spheroidal or subprolate in monads) tetrahedral tetrads, type of aperture 3-colporate in monads, 3-porate or 3-hemicolpate in tetrads, and presence or absence of margin and ornamentation of the sexine (striate-reticulate in monads) or microreticulate and variously reticulated in tetrads. These characters were important for identification both at the species and subtribe levels and were used in the pollen key presented herein.

Makino (1991) studying the pollen flora of the family Gentianaceae in the Reserva do Parque Estadual das Fontes do Ipiranga, described Centaurium erythraea, using light microscopy, to have pollen grains varying from subprolate to prolate spheroidal, 3-4 colpate, endoaperture lolongate and the sexine striate reticulate. The results found here were similar, differing only in the number and type of endoapertures. 

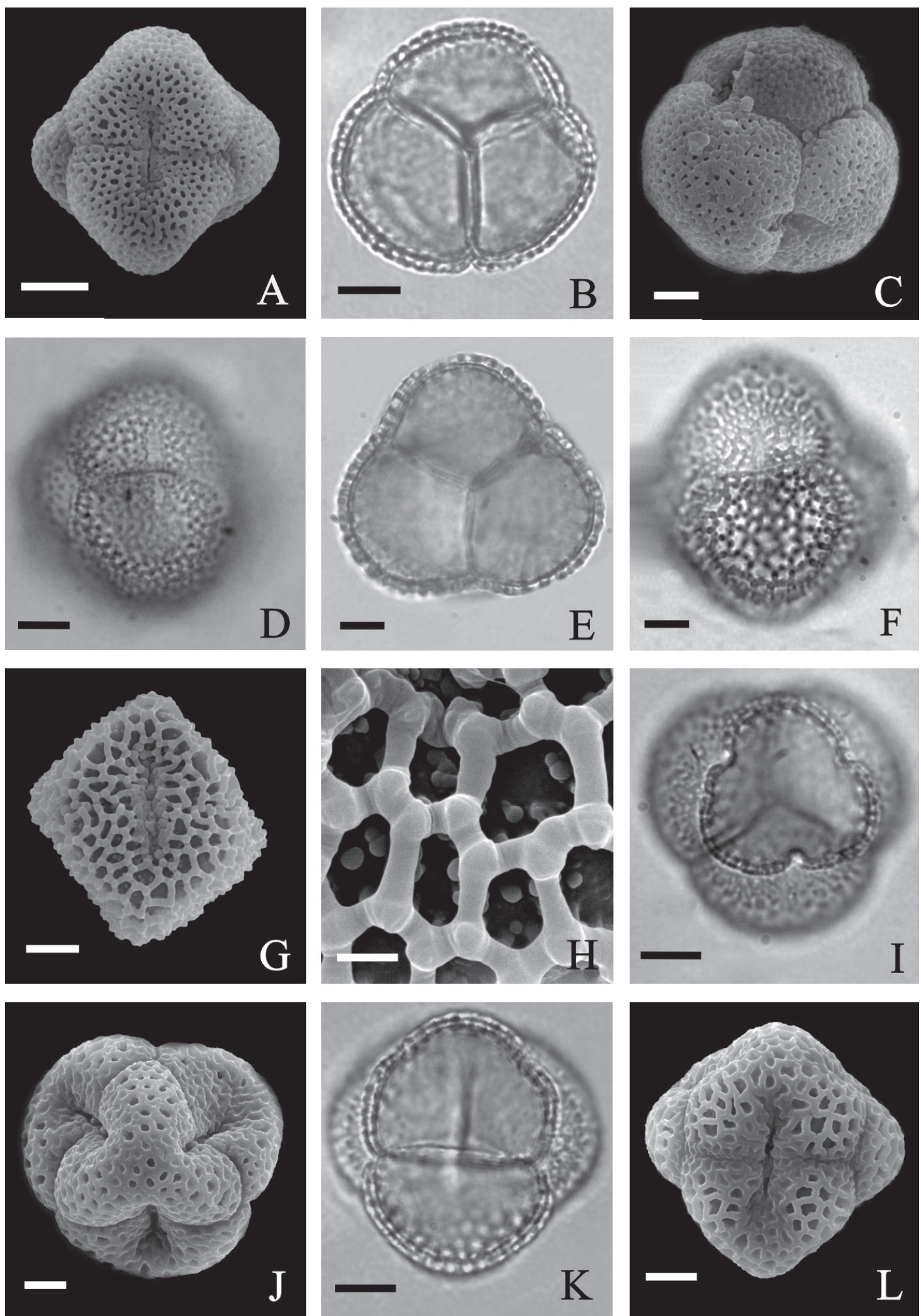

Figure 3. Photomicrographs and electron micrographs of pollen grains of species of Chironieae (Gentianaceae). A. Deianira damazioi - lateral view: general view (MEV). B-D. D. erubescens - basal view: B. optical section (ML), C. general view (MEV), lateral view: D. aperture detail (ML). E-H. Deianira nervosa - basal view: E. optical section (ML), lateral view: F. general aspect (ML), G. general aspect (MEV), H. surface detail (MEV). I-L. D. pallescens - apical view: I. optical section (ML), J. general aspect (MEV), vista lateral: K. optical section (ML), L. general aspect (MEV). Scales bar: A, B, D, E, F, G, I, J, K $=10 \mu \mathrm{m} ; C, \mathrm{~L}=5 \mu \mathrm{m} ; \mathrm{H}=2 \mu \mathrm{m}$. 
By analyzing the palynology of different botanical families occurring on Barro Colorado Island, Roubick \& Moreno (1991) described the pollen morphology, using light microscopy, of seven species of the family Gentianaceae, among them was Coutoubea spicata, which was described as having tricolporate tetrad, baculate sexine with bacula decreasing in size near the apertural region. The results obtained here differ from those of Roubick \& Moreno (1991) since the species was considered to have a 3-hemiporate tetrad with a reticulate sexine. The differences recorded here can be explained by the use of scanning electron microscopy, which allows a more detailed examination of the surface and the type of aperture.

In 2002, in his work "Gentianaceae: A Review of Palynology," Nilsson analyzed the pollen morphology of various representatives of the family and grouped species into pollen types. The author analyzed the genus Coutoubea (four species) and Deianira (six species), and recognized two types of pollen. The Coutoubea-type pollen is characterized by having colpate, colporate or porate tetrads, while the Deianira-type pollen is described as having 3-colpate tetrads. The results obtained here for the genus Coutoubea fit the type established by the author considering that condition of the apertures was found to be 3-porate. Also, the species of Deianira studied in the present work belong to the Deianiratype described by Nilsson (2002) since the tetrads have 3 hemicolpi.

This work represents the first pollen record for Deianira chiquitiana, D. damazioi and Zygostigma australe. A closer examination using scanning electron microscopy allowed a more thorough examination of the ornamentation of the sexine and the type of aperture.

\section{Conclusion}

The results obtained here demonstrate that the subtribe Chironiinae is characterized by possessing pollen grains in monads and a striate reticulate sexine, yet species differ in pollen grain shape and the detail of the endoaperture. The subtribe Coutoubeinae possesses pollen grains organized into tetrahedral tetrads and a reticulated and microreticulated sexine. The species of Coutoubea are separated from those of Deianira by the type of aperture (3-porate and hemicolpate, respectively). The species of Deianira were distinguished by the size of the tetrads and details of the ornamentation, which permitted the differentiation of the five species.

Thus, it is concluded that pollen morphology supports the delimitation of species and subtribes.

\section{Acknowledgements}

We are grateful to Camila Messias and Beatriz Cordeiro (Department of Invertebrates of the National Museum of the Federal University of Rio de Janeiro). The authors would like to thank the financial support by the Research Support Foundation of Rio de Janeiro State (FAPERJ) for lab supplies, and the National Council for Scientific and Technological Development (CNPq) for the research scholarship awarded to the authors.

\section{References}

Albert VA, Struwe L. 2002. Gentianaceae in context. In: Struwe L, Albert VA. (eds.) Gentianaceae: Systematics and natural history. Cambridge, Cambridge University Press.

BFG. 2015. Growing knowledge: an overview of Seed Plant diversity in Brazil. Rodriguésia 66: 1085-1113.

Chassot P, Hagen BK. 2008. Pollen morphology of the Swertiinae (Gentianaceae): phylogenetic implications. Botanical Journal of the Linnean Society 157: 323-334.

Crespo SEM, Marcondes-Ferreira W. 2006. Morfologia polínica dos gêneros Curtia Cham. \& Schltdl. e Hockinia Gardner (Gentianaceae Juss.). Acta Botanica Brasilica 20: 273-284.

Erdtman G. 1952. Pollen morphology and plant taxonomy Angiosperms. Stockholm, Almqvist \& Wiksell.

Faegri G, Iversen J. 1966. Textbook of modern pollen analysis. 2nd. edn. Copenhagen, Scandinavian University Books.

Ferreira MG, Absy ML, Gonçalves-Esteves V. 2012. Pollen morphology of the genera Irlbachia, Tachia, Voyria and Voyriella (Gentianaceae Juss.) found in the Reserva Florestal Adolpho Ducke (Amazonas, Brazil). Acta Botanica Brasilica 26: 916-923.

Gilg, E. 1895. Gentianaceae. In: Engler HGA, Prantl KAE. (eds.) Die Natürlichen Pflanzenfamilien. Vol. 4. Leipzig, Wilhelm Engelmann. p. 50-108.

Guimarães EF, Mendonça CBF, Gonçalves-Esteves V, Pereira JF. 2003. Palinotaxonomia de espécies de Schultesia Mart. Gentianaceae Juss. Arquivos do Museu Nacional 61: 151-164.

Makino H. 1991. Flora Polínica da Reserva do Parque Estadual das Fontes do Ipiranga (São Paulo, Brasil): 97 - Opiliaceae, 100 - Balanophoraceae, 133 - Gentianaceae. Hoehnea 18: 43-48.

Martinelli G, Moraes MA. 2013. Livro vermelho da flora do Brasil. 1st. edn. Rio de Janeiro, Instituto de Pesquisas Jardim Botânico.

Melhem TS, Cruz-Barros MAV, Corrêa MAS, Makino-Watanabe H, SilvestreCapelato MSF, Gonçalves-Esteves VL. 2003. Morfologia polínica em plantas de Campos do Jordão (São Paulo, Brasil). Boletim do Instituto de Botânica, 16: 1-104.

Myers N, Mittermeier RA, MitterMeier CG, Fonseca GAB, Kent J. 2000. Biodiversity hotspots for conservation priorities. Nature 403: 853-858. Nilsson S. 2002. Gentianaceae: a review of palynology. In: Struve L, Albert VA. (eds.) Gentianaceae: Systematics and natural history. Cambridge, Cambridge University Press.

Punt W, Blackmore S, Nilsson S, Thomas A. 2007. Glossary of pollen and spore terminology. Review of Paleobotany and Palynology 143: 1-81.

Roubik DW, Moreno PJE. 1991. Pollen and Spores of Barro Colorado Island. St. Louis, Missouri Botanical Garden.

Salgado-Labouriau ML. 1973. Contribuição à palinologia dos cerrados. Rio de Janeiro, Academia Brasileira de Ciências.

Struwe L, Kadereit JW, Klackenberg J, et al. 2002. Systematics, character evolution, and biogeography of Gentianaceae, including a new tribal and subtribal classification. In: Struwe L, Albert VA. (eds.) Gentianaceae: Systematics and Natural History. Cambridge, Cambridge University Press. p. 21-209.

Thiers B, et al. continuously update. Index Herbariorum: A global directory of public herbaria and associate staff. New York Botanical Garden's Virtual Herbarium. <http://sweetgum.nybg.org/science/ih/>. 3 Oct. 2015. 